\title{
Teatro en Buenos Aires. Julio y agosto de 2009
}

\section{María Silvina Persino}

Una vez más me vi en la necesidad de apostar a una cierta selección de obras que mi investigación previa me había sugerido, y una vez más debo obligarme a no incluir a todas ellas en este comentario. Como siempre, prefiero dejar afuera, primero de todo, a aquellas que no llegaron a cumplir mis expectativas, como espectadora y crítica de teatro exigente.

El Teatro San Martín, una de las salas dependientes de la Ciudad de Buenos Aires, ofrecía con Marat-Sade de Peter Weiss, un espectáculo impactante y perturbador. Los locos, personificando a las masas de pobres siempre a punto de estallar en rebelión, se alternan con el sofisticado diálogo ideológico de los dos personajes centrales, antagónicos en su visión del mundo. La actualidad de la obra de Weiss se manifiesta en la fuerte sugerencia de una historia cíclica en la que las revoluciones siempre terminan siendo traicionadas. El lugar dado al humor en esta puesta de Villanueva Cosse marca un alejamiento de la emblemática puesta de Peter Brook en 1964 (o al menos su versión cinematográfica que llega hasta nosotros). Por un lado, a los bufones-payasos como personajes cómicos se les añaden aquí las tres monjas-enfermeras. La gestualidad y acciones de los dos grupos, lo mismo que los textos expresados en un trabajo coral impecable, disparan la mayor parte del humor de la obra. Por otro lado, un componente de humor que aquí se aprovechó al máximo está en el letargo de Corday, la asesina de Marat, que cae dormida en los momentos menos oportunos, y en la obsesión sexual de Duperret que se desborda en ella y en las monjas. Poniendo a prueba la vigencia de los recursos brechtianos esenciales a la obra, las más de dos horas de teatro se pueblan de las entradas y salidas del mundo de ficción dentro de la ficción: las censuras del director del hospicio, las intervenciones del "autor-director" Sade, los textos apuntados a los locos-actores cuando los olvidan, y por supuesto, la narración del relator y las canciones. Por último, a diferencia de la puesta 


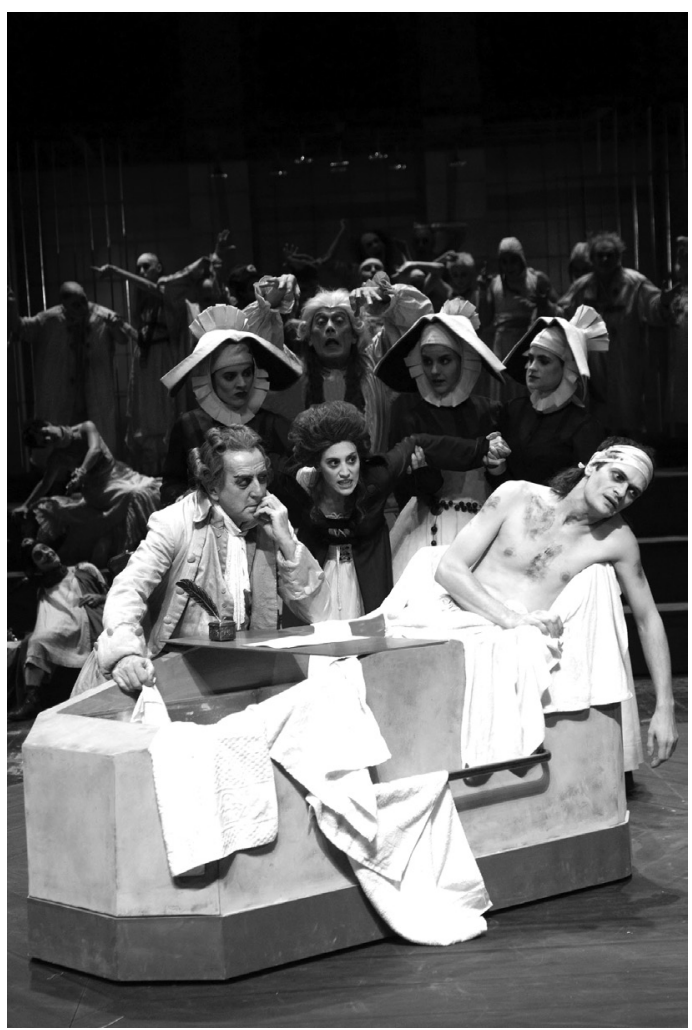

Marat-Sade Foto: Carlos Fuman

británica, no se usaron aquí actores para ocupar el lugar del público de la obra del hospicio, sino que se aprovechó a una parte del público real que había comprado las entradas para sentarse en dos tribunas en el escenario. Claro que entonces el final se aleja de Weiss y Brook: los locos no desataron el caos atacando a espectadores, monjas y guardas. Según Villanueva Cosse, concibió un final distinto de aquel imaginado en los sesenta, para "enfrentarnos con la insoportable situación de desconcierto, atonía o cinismo que, en términos generales nos separa y mucho de aquellos años, impregnados de esperanzas tanto sostenidas en flores como en llamamientos a las armas."

Si Marat-Sade deslumbra por su grandiosidad escénica y la trascendencia de su planteo ideológico, con Tú eres para mí estamos en el otro extremo, en el de la obra de pequeño formato, que se ocupa del más estricto día de las interacciones humanas. Es una creación (dramaturgia y dirección) de Mariana Obersztern, que viene ofreciendo excelentes obras como El aire alrededor (parte de Biodramas), Lengua madre sobre fondo blanco, y antes, en el "Proyecto Museos", Dens in dente, sobre el Museo Odontológico. Tú eres para mí tiene lazos muy claros con Lengua madre sobre fondo blanco, en su foco en los detalles, en la lupa puesta sobre el lenguaje, además del protagonismo de la talentosa María Merlino. Como en las otras obras de la directora-dramaturga, el humor sutil transita todo el espectáculo, aquí a través de la mirada de una mujer cuya impasividad produce, precisamente, más humor. Eli le dice a su pareja: "vos simplificás todo". Ella, precisamente hace lo contrario, deconstruyendo cada segmento de la conversación, volviéndolo 
objeto de disección y multiplicando, entonces, los sentidos posibles. La obra es simplemente eso, la recreación poética de una historia no-excepcional puesta bajo una lente que la magnifica.

En cambio, en Lote 77 el mundo es puesto en escena a través de una mirada masculina, y a su vez, es la masculinidad misma la que es problematizada hasta convertirse en el tema medular de la obra. El espectáculo, con dramaturgia y dirección de Marcelo Minnino, se va construyendo fragmentariamente, sobre la base de repeticiones y variaciones. A medida que avanza la obra, la interacción entre los tres jóvenes actores se intensifica y las repeticiones comienzan a justificarse como parte de un ensayo, pero no de teatro, sino de un intento de develar la construcción cultural que se esconde en el ser varón. De este modo, se va poniendo en evidencia la exigencia esclavizante que las expectativas culturales imponen al hombre. Toda la obra transcurre en un espacio donde se guarda el ganado vacuno (de allí el título) y se subraya cierto paralelo entre estos animales y los varones. De hecho, el programa de mano se entrega dentro de una bandejita de telgopor (styrofoam) envuelta en plástico transparente y con una etiqueta de precio, como si fuera un trozo de carne cruda comprada en el supermercado.

Los desórdenes de la carne (dramón de amor) nos habla de otra carne, la humana y de sus flaquezas. Vuelve con este espectáculo Alfredo Ramos,

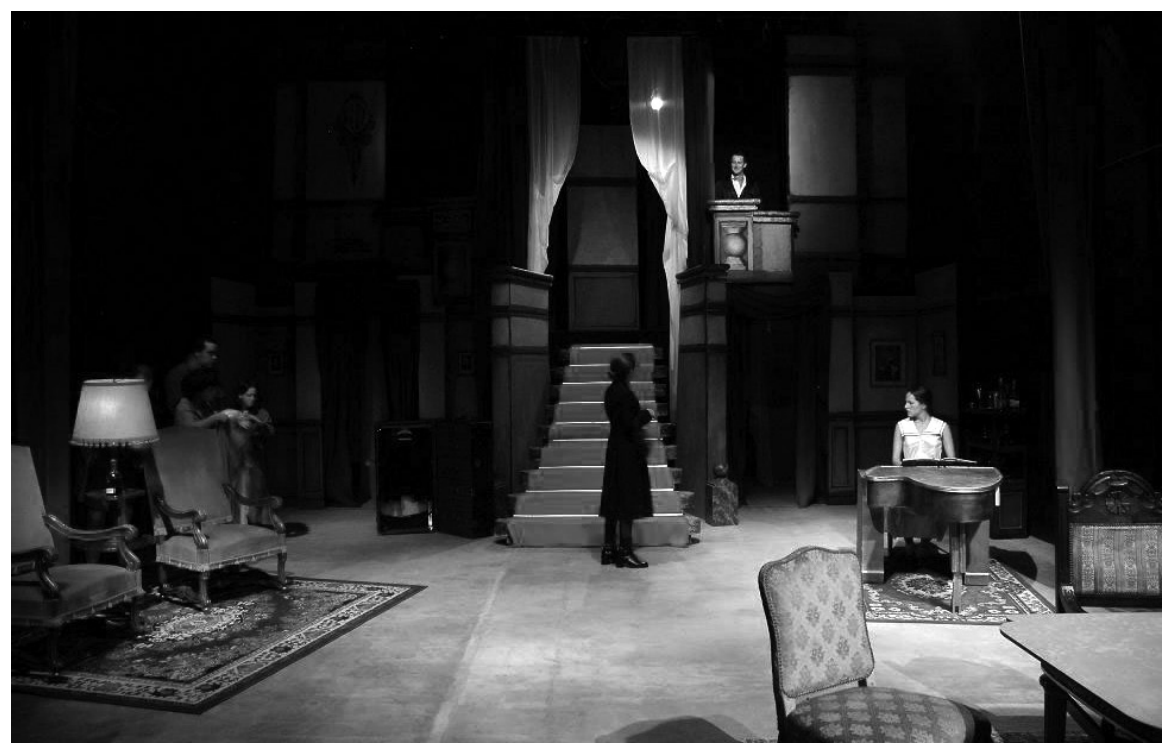

Los desórdenes de la carne (dramón de amor). Foto: Nicolás Levín 
responsable de la dramaturgia y la dirección, el mismo creador del maravilloso Un amor de Chajarí. Si aquella vez nos presentaba un grotesco rural, con esta obra nos enfrentamos a un código que recrea los años dorados del cine argentino, con sus excesos melodramáticos. No sólo estos excesos sino también la inteligencia del texto transitan permanentemente el humor. Llama la atención la grandiosidad y el realismo escenográfico de la escalera central con alfombra roja en una producción del off. Esa escalera - que ha sido uno de los puntos de partida de la creación de la obra, según comunicación personal de Ramos - resulta funcional en la obra y además, es símbolo de los valores de la clase dirigente ridiculizada en ella. La familia residente en la calle Alvear se siente amenazada por la masa de trabajadores que circula por Buenos Aires. Muy pronto se revela que la acción transcurre en los años cincuenta, durante los últimos años del gobierno de Perón.

El tema del peronismo también cobra cuerpo en la obra de Alejandro Tantanián, Mi muñequita o juremos con gloria morir. ${ }^{2}$ La dirección de Juan Carlos Fontana modificó lo que originalmente fuera un monólogo, añadiendo dos personajes. Además, se convocó al artista plástico Daniel Santoro para que se ocupara de la escenografía y el vestuario. A su vez, las imágenes del libro de Santoro, Manual del niño peronista, sirvieron de inspiración a Tantanián a la hora de escribir el texto. La intervención de este artista plástico resulta fundamental en la puesta, con el enorme vestido Dior de Eva Perón dominando la escena y el vidrio deformante tras el cual por momentos se oculta el personaje principal. Se trata de un espectáculo construido fragmentariamente donde los trozos de discurso aluden a próceres no reconocidos por la historia, a las esperanzas de los proletarios ante Evita, a los cuerpos embalsamados, robados y perdidos de la historia argentina. Hilándolo todo, la magnífica actuación de Cruz Zaikoski que alterna su registro expresivo desde un personaje afeminado y travestido a otro tosco y varonil. En definitiva, se agradece que el programa de mano anuncie la obra como "Una creación de Tantanián-Santoro-Fontana", ya que los tres, junto con los actores, han contribuido a construir un universo ambiguo y sugerente.

Este año había menos familias disfuncionales en la cartelera teatral de Buenos Aires. Una de ellas está en Adela está cazando patos, la obra creada y dirigida por Maruja Bustamante. En este espectáculo, la actuación es mucho más cercana al naturalismo que en todos los casos anteriores. Sin embargo, por momentos la obra se desborda de estos límites de dos maneras distintas y simultáneas: transita por isotopías fantásticas, delirantes, por un lado, y por otro, en esas instancias la actuación se sale de los límites del 
naturalismo y se instala en la farsa. La acción transcurre en algún espacio del noreste argentino y se invoca la (¿verdadera?) mitología del litoral para producir estos momentos de fantasía. La trama pasa de un ocio y malestar familiar, en un ambiente de calor bochornoso e incomodidad (fuertemente reminiscente del de La ciénaga, la película de Lucrecia Martel) a una trama policial, desencadenada por la reciente muerte del padre. Uno de los aciertos de la obra, que le valió al Grupo Capicúa el premio a la mejor escenografía Teatro del Mundo, es la piscina de lona llena de pequeñas pelotas de plástico azul. Los personajes se sumergen en ella y crean absolutamente la sensación de estar refrescándose dentro del agua.

Hay otras obras comentadas aquí que recibieron premios, y una de ellas es Tercer cuerpo, de Claudio Tolcachir, dramaturgo-director, quien ganó con esta obra el premio María Guerrero 2009 a la mejor obra de teatro. Es el mismo creador de la ya legendaria La omisión de la familia Coleman. Una vez más nos apretujamos en las sillas de Timbre 4 para ver lo que sucede en otro espacio abigarrado, el escenario. Esta vez el espacio es una oficina pública, aunque por momentos se le superpone otro espacio (¿una casa?) y entonces, en medio de los personajes de la oficina, una pareja dialoga su propia crisis sin que los otros tengan conciencia de ello. En alguna otra instancia, uno de los personajes se dirige a un interlocutor que no vemos y entabla un diálogo del que sólo escuchamos y vemos la mitad, todo en medio de los otros personajes que parecen entonces estar en otra dimensión y no advertirlo. Se diría que actores y director han hecho de las limitaciones un logro, tanto en este uso imaginativo del abreviado espacio escénico, como en los momentos en que suena el teléfono, alguien dice "ring", y todos reaccionan como si hubiera sonado verdaderamente un teléfono. Al final de la obra las historias convergerán y se crearán vínculos entre todos los personajes. Si bien las tramas dispersas que luego se reúnen parecen revelar un origen en la creación colectiva surgida de la exploración en los ensayos, hay necesariamente mucho del ingenio dramatúrgico de Tolcachir en los diálogos desopilantes y los precisos parlamentos de los personajes.

Por último, con diferencia de dos o tres semanas, Daniel Veronese estrenó dos obras basadas en otras de Ibsen. Ambas se presentan en la misma sala y con la misma escenografía, que a su vez había sido utilizada antes en Budín inglés, con dramaturgia y dirección de Mariana Chaud, nunca presentada en esta sala. ${ }^{3}$ Como en muchas de las creaciones de Veronese, los títulos son largos y enigmáticos. Para su versión de Casa de muñecas, eligió El desarrollo de la civilización venidera. Aunque notablemente reducida a una 
hora de teatro, se trata de una versión que, con algunas modificaciones, respeta la historia narrada por Ibsen e incluso rescata algunas frases textuales de la obra original. No obstante, el Dr. Rank es una doctora (que no termina muriendo) y en este sentido vale la pena apuntar que el cambio de género, como ocurría en su versión de Tres hermanas, pone en evidencia algunos aspectos de la construcción cultural mujer y hombre. ${ }^{4}$ Además, apenas comienzan a hablar los personajes, percibimos una anacronía: comentan una película que acaban de ver, que se identifica pronto con Escenas de la vida conyugal de Bergman, quedando así enfatizado como tema central el matrimonio. Por último, hay que advertir que Veronese deja el final de la obra en un lugar de ambigüedad: falta el histórico portazo y no podemos saber si el gran gesto de rebeldía e independencia de Nora se va a producir o no. Cabe agregar que la Nora compuesta por María Figueras es maravillosa, llena de energía lúdica hasta cierto momento, y luego quebrada por un dolor casi siempre contenido.

Por otra parte, la versión de Hedda Gabler concebida por Veronese se muestra bastante más alejada de su original, y lleva el título Todos los grandes gobiernos han evitado el teatro íntimo. Aquí el director juega mucho uno de sus juegos preferidos que consiste en romper la cuarta pared y mostrarse ostentosamente como teatro. Ya desde el comienzo (y esto también en Todos los grandes) los actores están en el escenario con total conciencia de los espectadores que van entrando, como si unos y otros habitaran un mismo espacio ontológico, ni más ni menos ficcional. Durante la obra, este límite poroso entre el afuera y el adentro teatral se desarrolla hasta el punto de volverse central en el espectáculo. Por un lado, hay momentos en que los personajes dicen sus parlamentos al público. Por otro, también hay construcciones en abismo de varias maneras. Los nuevos esposos viven, temporariamente, en un teatro, con lo cual hay referencias a escenografías y camarines (es que habitan, precisamente, la escenografía de la otra obra de Veronese). Además, Nora se reconoce como personaje sobre el que críticos escriben. Por último, se establece un vínculo intertextual-Veronese cuando el libro que Lovborg ha escrito se llama El desarrollo de la civilización venidera.

Al repasar los espectáculos incluidos aquí (y otros vistos pero no reseñados), con la excepción de Marat-Sade y Muñequita o juremos con gloria morir, estamos ante el fenómeno muy usual en la escena argentina: los directores que además son responsables de la dramaturgia. Posiblemente se deba apartar también el caso Veronese, que es un escritor de teatro que realiza un trabajo de escritorio intenso, antes de comenzar a ensayar una obra, aunque luego modifique el texto durante el proceso de ensayos. En los otros cinco 
casos, aunque no podría asegurar en qué medida los actores colaboraron en la creación de las obras, a riesgo de equivocarme, me atrevo a afirmar que hay un método común: se trata de obras que, partiendo de alguna idea germinal, han ido desarrollándose sobre el escenario, hasta que el director filtró y armó los materiales escribiendo la obra. ¿Creación colectiva? En este sentido, Federico Irazábal presentó una ponencia interesante en el último congreso de GETEA. ${ }^{5}$ Sugiere que la creación colectiva contemporánea en Argentina es sobre todo una técnica de trabajo usada en una primera etapa, que luego queda subsumida en el trabajo del director que se sienta después a ordenar y escribir el texto, firmado por él. Un factor que importa en este sentido es que, a diferencia de los grupos de los sesenta, setenta y ochenta, hoy no hay colectivos de trabajo que perduren en el tiempo, y eso es menos conducente a atribuir la autoría a un grupo. Además, dice Irazábal que la necesidad de preservar lo único no-efímero del teatro, que es el texto, junto con el mercado editorial, empujan al director a transcribir y publicar el texto con su autoría. En mi opinión, hay algo problemático en este borronear la experiencia de creación colectiva que está en el origen de estos espectáculos, sin siquiera un reconocimiento en el programa de mano. Un tema para seguir pensando.

\section{Trinity College}

\section{Notas}

Comunicación personal de Villanueva Cosse.

2 La segunda parte del título, con "oh" en lugar de "o", es parte del estribillo del himno nacional argentino: "Oh juremos con gloria morir".

3 No es la primera vez que Veronese "recicla" escenografías. En Espía a una mujer que se mata (su versión de Tío Vanya) usaba la escenografía que había usado en su Mujeres soñaron caballos. En mi opinión, es un gesto que señala que su creación no da un lugar significativo a la escenografía. Su teatro es contar una historia a través de la pura actuación (recordemos que en Una mujer que se ahoga los actores no usaban vestuario sino su ropa de calle, otro signo más del despojamiento de su teatro.).

4 Sobre este aspecto de la obra de Veronese puede verse mi ensayo "Chéjov según Veronese (Un hombre que se ahoga)". Revista Conjunto 143 (2007): 26-32.

5 XVIII Congreso Internacional de Teatro Iberoamericano y Argentino, Buenos Aires, 4-8 de agosto de 2009. 
